\title{
Nuclear Energy
}

\author{
Parashu Ram Poudel \\ Department of Physics, Prithvi Narayan Campus, Pokhara \\ parashupoudel@hotmail.com
}

\begin{abstract}
Nuclear energy is the latest energy source to be used on a large scale. It has tremendous potentiality to meet the growing demand of energy without degrading the environment. Presently the nuclear fission of some heavy elements of the periodic table produces the vast majority of nuclear energy in the direct service of humankind. So nuclear energy produced by nuclear fission and its impacts are the main focus of this article.
\end{abstract}

Keywords: Reactor Grade Uranium, Nuclear power plant, carbon-zero, Radioactive Waste

\section{INTRODUCTION}

Energy is defined as the capacity of doing work. It has been crucial factor to humane survival. The exploitation of new sources of energy has been central to human progress from the early Stone Age to today's technological world to fulfill the need for survival. It is the most reliable indicator of a country's development. Quality of life is strongly correlated with per capita energy consumption. Nature provides energy in many different ways. The primal source of energy on the earth is the sun. Every substance in nature is a storehouse of energy. These energies can be extracted following suitable processes.

Nuclear energy is the energy that comes from the nucleus of an atom. It is released by a nuclear reaction either through nuclear fission or nuclear fusion. In fact the universe is powered by nuclear energy and the life on this earth oweds its existance and the sustenance to the sun which shines brightly receiving copios of energy from nuclear fusion. In nuclear fission the energy is released by splitting the nucleus of a heavy atom into two more or less equal fragments by a neutron blasting through the nucleus. This makes other neutrons fly off at high speeds. Eventually, it establishes a chain reaction. Nuclear fusion is the opposite term by which the nuclei of two or more lighter atoms fuse together to form a heavier one. In both processes mass is lost and this is then converted into energy according to Einstein's famous mass energy equivalent relation $\mathrm{E}=\mathrm{mc}^{2}$. The energy released is then converted into heat which can be used to drive a turbine and generate electricity.
Nuclear energy is one of the most efficient sources of energy available. It produces more energy than any other fuel of the same mass or volume. It does not produce any direct air pollution or greenhouse gases. It represents only about $15 \%$ of the electricity produced worldwide and it represents a very small percentage in many countries' total electricity production. But this percentage is likely to go up in the coming years. There is an ongoing debate about nuclear energy whether it is a safe, sustainable energy source that reduces carbon emissions or a highly risky and dangerous for human beings.

\section{HISTORICAL DEVELOPMENT}

A German chemist named Martin Heinrich Klaproth is credited for discovering uranium in 1789. Later it was named after the planet Uranus, the Greek God of the sky. However, Eugene Melchor Peligot was the first person who isolated the metal in 1841. Wilhelm Rontgen had discovered ionizing radiation in 1895 by passing an electric current through an evacuated glass tube and produced continuous X-rays.

In 1896 Henri Becquerel found that pitchblende that contained radium and uranium actually caused a photographic plate to become dark. He went on to demonstrate that this was due to the emission of beta radiation and alpha particles. Villard found a third type of radiation from pitchblende. It was gamma rays, which were the same as X-rays. Then in 1896, Pierre and Marie Curie gave the name 'radioactivity' to this phenomenon. Radium was later used in medical treatment. In 1898, Samuel Prescott showed that radiation destroyed bacteria in food 
In 1902, Ernest Rutherford showed that radioactivity as a spontaneous event does emit an alpha or beta particle from the nucleus to create a different element. He went on to develop a fuller understanding of atoms and in 1919, he fired alpha particles from a radium source into nitrogen. In this way he found that nuclear rearrangement was occurring with the formation of oxygen.

Niels Bohr was another scientist who enlarged our understanding of the atom. By 1911, Frederick Soddy discovered that natural-radioactive elements had a number of different isotopes (radionuclide). In 1911, George de Hevesy showed that such radionuclides were invaluable as tracers, because minute amounts could readily be detected with simple instruments. In 1932, James Chadwick discovered the neutron. Also in 1932, Cockcroft and Walton produced nuclear transformations by bombarding atoms with accelerated protons. Likewise, in 1934 Irene Curie and Frederic Joliot found that such transformations created artificial radionuclides. The next year Enrico Fermi found that a much greater variety of artificial radionuclides could be formed when neutrons were used instead of protons.

Fermi continued his experiments. He mostly produced heavier elements from his targets but also with uranium. Some of them were much lighter ones. At the end of 1938, Otto Hahn and Fritz Strassmann in Berlin showed that the new lighter elements were barium and others were about half the mass of uranium. This has proved that an atomic fission had occurred. Lise Meitner and her nephew, Otto Frisch, worked under Niels Bohr and explained that the neutron was captured by the nucleus. Actually due to extreme vibration, it caused the nucleus to split into two parts. They calculated the energy release from this fission which were about 200 million electron volts. Frisch confirmed this figure in January 1939. This was the first experimental confirmation of Albert Einstein's paper that suggested the equivalence between mass and energy. In the 1930s and 40s, this energy was largely used as military weapons by technically advanced nations. The Manhattan Project successfully used this energy in a chain reaction to create nuclear bombs. Immediately after the end of World War II, the newfound energy source was used in the nuclear navy. It provided submarines an amazing capacity to run its engines for over a year without refueling. During 1939-40 development of atomic bomb was focused. From 1945 attention was given to harnessing this energy in a controlled fashion for naval propulsion and making electricity. Since 1956 prime focus has been on the technological evolution of reliable nuclear power plants. In later years, this technology was quickly transferred to the public sector where commercial power plants were developed. Main events are summarized in points in the timeline given below:

\section{Timeline of the Development of Nuclear Energy} 1789- Martin discovered Uranium 1895-Roentgen discovered X-rays 1896- Becquerel discovered rays emitted spontaneously from uranium salts 1898-The Curies identified two radioactive nuclides, coin term "radioactive"

1899- Rutherford distinguished alpha and beta radiation and discovered half-life

1909- Rutherford discovered that most mass is concentrated in a small nucleus

1920- Rutherford theorized a "neutron"

1935- Chadwick identified neutrons

1938- Hann and Strassman split uranium atoms with neutrons, Meitner and Frisch explained what's happening and name it "fission"

1939- Fermi and Szilard measured neutron multiplication, concluded that a nuclear chain reaction is possible

1939- Szilard, Wigner, and Teller convinced Einstein to sign a letter warning Roosevelt of possibility of nuclear weapons

1939- Roosevelt authorized creation of Advisory Committee on Uranium, begins US nuclear bomb effort (though not vigorously) 1942- Fermi achieved first nuclear chain reaction in a squash court at $U$. of Chicago. Manhattan project in full swing. Secret cities are built in Oak Ridge TN (to enrich uranium), 
Hanford WA (to produce plutonium), and Los Alamos NM (to design and assemble bomb) July 1945- The world's first nuclear weapon tested, the Trinity shot, was successful

Aug 6 \& 9, 1945-Atomic bombs Little Boy and Fat Man dropped on Japanese cities, Hiroshima and Nagasaki. Up to 240,000 people died.

Aug 15, 1945- Japan surrendered unconditionally, ending WWII.

1951-EBR-1 reactor was the first to generate electricity in Arco.

1953- Eisenhower gave Atoms for Peace speech, launching civilian program

1954- Obninsk reactor in the Soviet Union become the first commercial nuclear power plant

1954- USS Nautilus launched, the first nuclear-powered submarine

1957- Shippingport reactor began operation, first commercial nuclear power

1974- French Prime Minister Messmer launched huge nuclear power program in response to oil crisis. In 2004, 75\% of France's electricity was nuclear

1979- Three Mile Island reactor suffered a partial meltdown. Radiation largely contained Created by hatisnuclear.com.

1986- Chernobyl reactor suffered a large power excursion resulting in the release of large amounts of radiation. $50+$ fire fighters die, up to 4000 civilians estimated to have died of early cancer

1986- EBR-II reactor demonstrated that advanced, sodium cooled reactors can passively shut down without backup systems 1994- Megatons to Megawatts program started, turns 20,000 nuclear weapons into electricity. By 2000, 10\% of US electricity came from dismantled Russian warheads 2004- After decades of electricity generation with no deaths in the US, a Nuclear Renaissance discussed, with talks of more reactor builds to offset carbon emissions 2011- Four reactors at Fukushima Daiichi losed backup generators due to tsunami and suffer core meltdowns, hydrogen explosions. Radiation release estimated 10-30\% of Chernobyl. Zero people's health affected by dose, but land was evacuated

2013-Climate guru James Hansen published paper claiming nuclear has saved 1.8 million lives total (including worst-case estimates for all accidents) by offsetting air-pollution related deaths

2013- Voyager I entered interstellar space after traveling the solar system for 36 years. It was powered by a Plutonium-238 radioisotopic thermal generator

\section{ENERGY DENSITY OF VARIOUS FUEL SOURCES}

The energy density is the energy stored in a unit mass of the substance. The amount of energy released in nuclear reactions is astounding. The natural uranium undergoes nuclear fission and thus attains very high energy density. Table below shows energy density of various sources.

\begin{tabular}{|l|l|l|}
\hline \multicolumn{1}{|c|}{ Material } & $\begin{array}{c}\text { Energy } \\
\text { Density } \\
(\mathrm{MJ} / \mathrm{kg})\end{array}$ & $\begin{array}{c}100 \mathrm{~W} \text { light } \\
\text { bulb time } \\
(1 \mathrm{~kg})\end{array}$ \\
\hline Wood & 10 & 1.2 days \\
\hline Ethanol & 26.8 & 3.1 days \\
\hline Coal & 32.5 & 3.8 days \\
\hline Crude oil & 41.9 & 4.8 days \\
\hline Diesel & 45.8 & 5.3 days \\
\hline $\begin{array}{l}\text { Natural Uranium } \\
(>99.2 \% \text { U-235 \& } \\
0.72 \% \text { U235) }\end{array}$ & $5.7 \times 10^{5}$ & 182 years \\
\hline $\begin{array}{l}\text { Reactor Grade } \\
\text { Uranium }(3-4 \% \mathrm{U}-235)\end{array}$ & $3.7 \times 10^{6}$ & 1,171 years \\
\hline
\end{tabular}

Table 1. Energy densities of various energy sources. All numbers assume $100 \%$ thermal-to-electrical conversion.

\section{NUCLEAR POWER STATIONS IN THE WORLD}

Just as many conventional thermal power stations generate electricity by harnessing the thermal energy, nuclear power plant converts the energy released from the nucleus of an atom via fission that takes place in a nuclear reactor. Major components of a nuclear reactor are Core, 
Coolants, Control rods, Moderators, Steam Generator and Turbine Generator. The heat is removed from the reactor core by a cooling system that uses the heat to generate steam which then used to run turbine to produce electricity. A figure below shows a nuclear power plant.

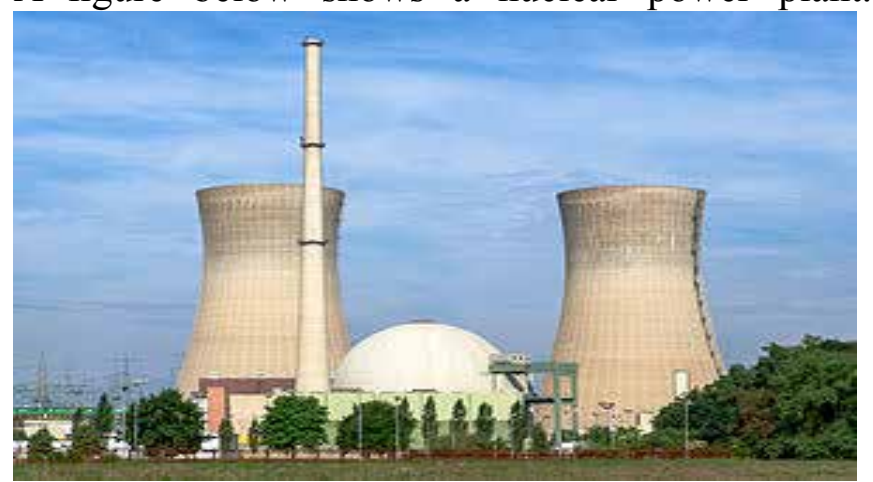

Fig 1: A nuclear power station (Grafenrheinfeld Nuclear Power Plant, Grafenrheinfeld, Bavaria, Germany). The nuclear reactor is contained inside the spherical containment building in the center - left and right are cooling towers, which are common cooling devices.

There are 31 countries in the world where currently nuclear power stations are operated. A number of new reactors are being built in China, South Korea, India, and Russia. Of the 31 countries where nuclear power plants are operated, only France and Belgium use nuclear energy as the primary source of electricity. The major fifteen countries of the world, which operate nuclear power, are as follows: Table-2 Major countries of the world, which are operating nuclear power.

\begin{tabular}{|c|l|c|c|}
\hline Rank & Country & $\begin{array}{c}\text { Capacity } \\
\text { (MW) } \\
(2014)\end{array}$ & $\begin{array}{c}\text { Nuclear share of } \\
\text { electricity } \\
\text { production, } \\
2013\end{array}$ \\
\hline 1 & USA & 99,081 & $19.4 \%$ \\
\hline 2 & France & 63,130 & $73.3 \%$ \\
\hline 3 & Japan & 42,388 & $17.1 \%$ \\
\hline 4 & Russia & 23,643 & $17.5 \%$ \\
\hline 5 & South Korea & 20,721 & $27.6 \%$ \\
\hline 6 & China & 17,978 & $2.1 \%$ \\
\hline 7 & Canada & 13,538 & $16.0 \%$ \\
\hline 8 & Ukraine & 13,107 & $43.6 \%$ \\
\hline 9 & Germany & 12,068 & $15.4 \%$ \\
\hline 10 & Sweden & 9,474 & $42.7 \%$ \\
\hline 11 & UK & 9,243 & $18.3 \%$ \\
\hline
\end{tabular}

\begin{tabular}{|c|l|c|c|}
\hline 12 & Spain & 7,121 & $19.7 \%$ \\
\hline 13 & Belgium & 5,927 & $52.1 \%$ \\
\hline 14 & India & 5,308 & $3.5 \%$ \\
\hline 15 & Taiwan & 5,032 & $19.1 \%$ \\
\hline
\end{tabular}

\section{ADVANTAGES OF NUCLEAR ENERGY}

Clean Energy: Nuclear energy can produce electricity without greenhouse gases in the atmosphere. That means nuclear energy produces electricity without causing pollution. It is cleaner than many other forms of energy produced today. Essentially, nuclear power would be "carbon-zero" if they are stored and transported in a more efficient way.

High Quantities: Nuclear reaction can produce a million times more energy as compared to hydro or wind energy. Only a single power plant has the capacity to produce a large quantity of energy. Since it does not use fossil fuel, hence it will obviously decrease our dependency on oil.

High Reserves: Nuclear reactors use uranium as fuel and produces huge amounts of energy. The Earth has the high reservoir of uranium. It is believed that the earth has abundance store of uranium that can last for several years. Moreover, other fuel cycles like Thorium are also available for power generation. Whereas, oil reserves and other fossil type fuels are likely to run out shortly.

Reliability: Nuclear power plants operate reliably and have a continuous output of power. The energy level is not affected by the weather conditions, unpredictable costs, or foreign supplies. One of the special features of this plant is that it can run for about 500 to 700 days continuously, before they are shut down for refueling. The plants do not generally face operations and maintenance problems. This is a contrast to other alternative energies, which are highly affected by the influence of weather.

Low Operating cost: Nuclear energy produces electricity at a competitive price and it is generally compared with coal plants. It is sustainable and can be harnessed for several years from now. Although 
nuclear power reactors are expensive to build, they are relatively cheaper to operate. Let's not forget that the supply of fuel is limited and therefore it has always been expensive. A plant can be operated by small number of people.

Concentration: The nuclear energy is by far the most concentrated form of energy. It can be produced in large quantities even in a short period. It has wonderful capacity to generate high amount of electrical energy for the power plants.

Low Waste: It generates less wastages overall than other energy plants. The wastes resulting from the operation of all nuclear power plants produce not more than 10,000 tones of spent fuel, a small amount compared to other energy sources. If the electricity is generated by the combution of coal it would result in millions of tons of $\mathrm{SO}_{2}$, in addition to billion tons of $\mathrm{CO}_{2}$ and poisons heavy metals. At the same time, nuclear waste is more easily disposable than fossil fuel wastes.

Location: A nuclear plant does not depend on local sources like oil and coal and can be set up in convenient places. It also does not require a lot of space to set up and the power does not have to be transferred over long distances.

Knowledge: Nuclear power development has multiple uses and advantages. Its systematic study can provide knowledge to open many doors of possibilities.

Environmental Safety: The process to generate nuclear energy is one of the cleanest processes. It has least impacts on the environment because nuclear plants do not emit harmful gases like carbon dioxide, nitrogen oxide and sulphur dioxide. However, the conventional electricity power plants emit harmful gases, which threaten atmosphere by increasing global warming. The energy produced from nuclear plants is 'emission-free'. Since it requires little land to run the plant, there is no need to encroach forest to make additional land. There are no adverse effects on land, water, and air resources. It is claim that nuclear energy as a whole saved millions of lives by offsetting the air pollution related death that come from fossil fuel plant.

Reduces the dependency on fossil fuels: Owing to increased volume of transportation, there is an increased demand of fossil fuels like oil and gases in the world. Because of this, its stock is rapidly running out. In contrast, nuclear energy requires very little quantity of fuel to produce large quantities of energy. For instance, one ton of uranium can produce energy that is more than several million tons of coal and oil. The rise in oil prices and the increased concern about environmental protection from $\mathrm{CO}_{2}$ emission have promoted attraction to the use of nuclear power as viable energy source of generation.

\section{USES OF NUCLEAR ENERGY}

Despite some risks, nuclear energy is much safer to be used to achieve many desired results. It can be used in diversified fields from peaceful purposes to electricity generation or medicinal manufacturing. In the recent past, there has been great advancement in using nuclear energy for peaceful purposes.

Food Irradiation: Food irradiation kills bacteria, insects and parasites that can cause food born diseases such as salmonella, trichinosis and cholera. In addition to killing bacteria, irradiation can retard spoilage and increase the shelf life of food. The doses needed for those purposes are too low to destroy diseases causing bacteria. Food irradiation does not make the food radioactive, and it does not change the food any more than canning or freezing.

Agriculture: In agriculture radiation helps breed new seed varieties with higher yields. Agricultural researcher also use radiation to develop hundreds of varieties of harder, more disease resistant crops including peanuts, tomatoes, onions, raisin, soyabeans, barley etc.; To improve the nutritional value of some crops, as well as to improve their baking or melting qualities to reduce their cooking time; and to show how plants absorb fertilizer which helps researchers to learn when to apply them and its quantity. Leading organizations have been 
working on the technology to increase agricultural production, improve food availability, reduce production costs and minimize pollution of food crops. The major ongoing advancement is Sterile Insect Technique (SIT) that helps in large-scale food irrigation and biological control of pests.

Human Health:Anapplication ofradiotherapyhasbeen proved highly successful to treat cancer patients. At the same time a small amount of radioisotope tracer is used for diagnostic and research purposes. The radioisotopes help in detecting various enzymes, hormones and many other substances present in the human blood. These techniques have also helped in monitoring the levels of toxic substances in food, air and water.

Sterilization: Gamma emissions are much popular for the sterilization of medical supplies like cotton, bandages, gloves, syringes, burn dressings, etc. which help to prevent the spread of diseases. Exposing these materials to radiation does not make them radioactive.

Tracing Pollutants: Radioisotopes are used to trace the pollutants present in air. Even in small amount of the radioisotope presents in air can be very harmful to humans. Hence, the tracing quality helps to detect the residue easily. This way it ensures a healthy and safe environment.

Determination of Age: The nuclear energy has also been used by the archaeologists, geologists and anthropologists in determining the age of rocks, insects, and fossils.

Power in Space: Nuclear power has been actively used to provide power for the missions in space. Unmained space craft relay on radioisotope thermoelectric generator (RTG) for the power they need for space exploration. RTG use heat from plutonium to generate electricity. They are safe, reliable and long lived even in the harse climate of our solar system. The craft uses this electricity to run the computer and collect the vast area of data including images that are send back to earth.
Power in Sea: Nuclear Power is particularly suitable for vessels which nead to be at sea for long period without refuling. These vessels (ships/submarines) have a small nuclear reactor on board, which produces steam to run turbines. These turbines directly drive the propellers as well as electrical generators. Today, a large number of nuclear-powered ships and submarines are cruising the oceans.

Power Generation: The most important use of nuclear energy is to generate electricity. The energy released by the fission in a nuclear reactor is converted and generated into electricity. Besides this during the process of decaying, the radioisotopes emit lots of energy. This energy is used to control the heart pacemaker to provides power to the satellites for navigation.

Industry: Nuclear energy is being used in industries for processing and producing various products such as automobile, aircraft, mining, oil refinary, construction, etc. Nowadays the gamma rays emitted by the radioisotopes are used to check the leakages from the gas and oil pipelines, blockage in water pipes. The radioactive source is placed inside the pipe and the film outside the welds. This is so convenient that it can be used in place of X-ray equipment.

Use in Scientific Research: Researchers in the fields of science use nuclear radiation and radioisotopes in their work. Safety and effectiveness of new drugs are tested with radioisotopes. Radioisotopes are also essential to the biomedical research that seeks causes and cores for many diseases such as cancer, AIDS, etc. Researchers also use radioisotopes in metabolic studies, genetic engineering and environment protection.

\section{DISADVANTAGES OF NUCLEAR ENERGY} Nuclear Weapons Threat: Nuclear proliferation has posed a serious threat to the world peace. There are some reactors, which produce plutonium. This substance can be used to make lethal nuclear weapons. It is only due to a huge stock of nuclear 
weapons the world civilization has come under a serious threat. The world has already witnessed the ruthless devastation of nuclear power on Hiroshima and Nagasaki.

High Capital Investment: Nuclear Plants require a high level of technology and a major initial capital investment. Its abandonment cost is also very high.

Long Gestation Period: It takes about 15-20 years to develop a single plant. It requires extensive planning and careful observation.

Radioactive Waste: The nuclear wastes contain radioisotopes, which stay in the atmosphere for a long period. These reactive substances have acute capacity to contaminate the surrounding atmosphere to a great deal. The mixed wastes cause hazardous chemical reactions, which can lead to dangerous medical complications. The waste produced by nuclear reactors needs to be disposed off at a safe place. A bit of carelessness could be the cause of serious radiations. The storage of radioactive waste has become a serious problem even to before the experts. Until now, the radioactive wastes are buried under sand and the process is known as verification. There are issues with management of radioactive waste. The spent fuel is highly radioactive and therefore such wastes have to be carefully stored for many years after use.

Disasters, Accidents \& Risk: Even a minor accident in the nuclear plant may cause a major disaster. It could be the result of massive human casualties. The radiation stays for longer time in the atmosphere that could be the cause of serious medical complications to the loss of life. If we look back in the past, there was an explosion of a reactor at Chernobyl Nuclear Power Plant in Ukraine. It had massive effects as the radiation melted the core of a reactor at Three-Mile Island in the United States.

Non-renewable energy: Nuclear energy is an alternative energy, but not a renewable energy. Uranium is a non-renewable source of energy and its supply is limited.
Terrorism: Nuclear plants are vulnerable targets of terrorists. They always look for an opportunity to damage such plants. That's why these terrorists want to attack the plant and cause more human casualties. If anything like this happens, this might lead to a horrific disaster. Not only terrorists but also enemy nation might carry a military attack to cause serious damage to these nuclear energy plants.

Nuclear Accidents: New technologies have been introduced to make sure that no disaster should occur in nuclear plants. However, we cannot forget about an accident that had taken place at Chernobyl and more recently in Fukushima. Let's not forget that even a small radiation could be the cause of devastative effects. It has been found that people who work at nuclear power plants or live near those areas are at high risk of facing nuclear radiations.

Nuclear Radiation: High dose nuclear radiation is very harmful if leaked out to the environment. Ionising radiation affects health causinng the change in the cell of the human body. It does this by breaking the chemical bonds that hold together groups of atoms called molecules. For example DNA molecules, which contains a person's genetic information, control the chemical and physical functions of human cells. Damage to DNA molecule affects the ability of the cells to do their work and to pass information to new cell.

\section{PROBLEMS WITH NUCLEAR POWER}

Safety issues: Until today, three major accidents have already occurred in the commercial power plants: Chernobyl, Three Mile Island, and Fukushima. Chernobyl was an uncontrolled steam explosion, which released a large amount of radiation into the environment. The accident took the lives of over 30 people. The government had to evacuate the city dwellers to a safe place. Later, due to radiation in the atmosphere over 2000 cancer cases had been reported. Three Mile Island case was a partial-core meltdown. The coolant levels dangerously dropped below the fuel and allowed some fuel to melt down. 
In this accident, no one was hurt and very little radiation was released. Nevertheless, the plant had to be shut down. This caused massive financial loss to the investors. An enormous Tsunami wrecked havoc as it badly damaged Fukushima nuclear plant. Four active plants lost their cooling system and the heat melted the cores and caused radiation. The Japanese government swung into action and transported all the people from the area to a safe place. These three accidents are very scary and keep many people from being comfortable with nuclear power.

Nuclear Waste Management: Nuclear waste is the radioactive material that nuclear fuel becomes after it is used in reactor. It is biproduct of nuclear technology. Nuclear power reactors generate a lot of waste like any power reactor and considerable waste material like any fossil-fulled reactor. But nuclear waste need to be treated differently since they are not only toxic but also radiactive. Operation \& maintanance of nuclear reactor generates a variety of radioactive waste. The smaller atoms split and emit energetic particles can also cause biological damage. Some of the longest-lived atoms can even survive for a long time. These materials thus needed to be handled with utmost care.

Cost: Nuclear power plants are larger and more complicated than other power plants. More efforts are made to keep these plants operate safely. This complexity causes the up-front cost of a nuclear power plant go much higher. However, once the plant is built the fuel costs are much less than fossil fuel. It is also true that the older a nuclear plant gets it gives more financial benefits. The need of a large capital investment entices potential investors to finance nuclear power plants. Meanwhile, anti nuclear activities create more obstacles on the path of its establishment. Hence, to set up a nuclear plant has become more challenging.

\section{CONCLUSION}

Nuclear energy is one of the most efficient sources of energy available today, produces no direct air pollution or greenhouse gases. It is obvious that nuclear energy is the most viable solution of energy problems, and is very safe when used properly. Many countries have used nuclear energy for their economic development. The power of nuclear energy must be used for the betterment of the world. It depends upon humans to make nuclear energy a boon for allround development of human civilization. Without doubt, nuclear energy can successfully replace fossil fuels in days to come. With the help of modern technology and understanding, we will someday be able to use nuclear energy in everyday life.

\section{REFERENCES}

1. Alan Isaacs, Dictionary of Physics,1996 Oxford University Press New York

2. Arbin K.,Chitra N.,Atom and Development, 2006,HBCSE,Mumbai, India

3. Arthur Beiser,Concept of Modern Physics, Fifth Edition, 1999, Mc GRAW Hill New York

4. Encyclopedia Britanica,2013

5. John Ritch, The Necessity of Nuclear Power: A Global and Environmental Imperative 2008, World Nuclear Association

6. Microsoft corporation, Encarta, 2012, Microsoft corporation

7. Nari Mistry, A brief introduction to particle physics, 2000, Cornell University,USA

8. Niel Walet,Nuclear and Particle Physics,2003,UMIST,Manchester UK

9. Poudel P., Gautam A., Adhikari B., Thapa M., Khatry M.,Principles of Physics for class XII,2010, Ayam Publication Kathmandu, Nepal

10. Roger J Blin Stoyle,EUREKA ! Physics of particles, matter and the universe:1997 Institute of physics publishing, Bristol Philadelphia, USA

11. V. Devanathan, Nuclear Physics, 2012. Narosa Publishing House.

12. Vaidyanathan G.Nuclear Reactor Engeenering,2013 S. Chand Publication, New Delhi

13. Verma R.C., Mittal VK, Gupta S.C., Introduction to nuclear and particle physics 2013, PHI learning private limited.

14. Wikipedia, the free encyclopedia, en.wikipedia.org/wiki(obtained:2014.07)

15. Young and Freedman,University Physics, 12 th Edition,2009,Pearson Education, New Delhi,India 